\title{
Primary prevention of diabetes mellitus: current strategies and future trends
}

\author{
Prasanta K. Bhattacharya, Aakash Roy \\ Department of General Medicine, North Eastern Indira Gandhi Regional Institute of Health and Medical Sciences, Shillong, India
}

\begin{abstract}
Aim of this paper is to find evidence for primary prevention of type- 2 diabetes mellitus $\left(\mathrm{T}_{2} \mathrm{DM}\right)$ from epidemiological studies and clinical trials, and the feasibility of applying these interventions in resource limited countries. $\mathrm{T}_{2} \mathrm{DM}$, which accounts for more than nine-tenths of all diabetics, results from inadequate insulin secretion or underlying insulin resistance. The prevalence of diabetes, mainly $\mathrm{T}_{2} \mathrm{DM}$, has increased rapidly during the last few decades worldwide. Since the genetic background is unlikely to change during this short time period, the growing epidemic of $\mathrm{T}_{2} \mathrm{DM}$ is more likely due to changes in environmental or lifestyle risk factors including obesity, physical inactivity, smoking, alcohol and stress. The scope and feasibility for primary prevention of $\mathrm{T}_{2} \mathrm{DM}$ is based on elimination of these risk factors. This evidence that $\mathrm{T}_{2} \mathrm{DM}$ is preventable comes from epidemiologic studies and clinical trials of effect of lifestyle changes and drugs in development of $\mathrm{T}_{2} \mathrm{DM}$. The positive effects are more profound and safer with lifestyle modifications (LSM) compared to medications. This is shown to be effective globally, across various ethnicities and races and sustainable on long-term follow-up. However, there is a major challenge in translating this evidence into economically viable and sustained community programs, as these LSM interventions are expensive, even from western standards point of view. Future plan should focus on health education of the public, improving the national capacity to detect and manage the environmental risks including strategies to reduce stress, and development of innovative, cost effective, and scalable methodologies.
\end{abstract}

\section{Introduction}

Diabetes mellitus is a group of metabolic diseases whose common feature is an elevated blood glucose

Correspondence: Prasanta Kumar Bhattacharya, Department of General Medicine, North Eastern Indira Gandhi Regional Institute of Health and Medical Sciences (NEIGRIHMS), Mawdiangdiang, Shillong - 793018, India.

Tel.: +91.9435030138. E-mail: pkbdr78@gmail.com

Key words: Diabetes mellitus; type-2 diabetes mellitus; risk factors; primary prevention; lifestyle modification.

Contributions: PKB conceived the idea, did literature search and data collection, wrote and proofread the text, and made the final presentation. AR helped in writing the text and arranging the references.

Conflict of interest: the authors declare no potential conflict of interest.

Received for publication: 6 August 2015.

Revision received: 29 March 2016.

Accepted for publication: 30 March 2016.

This work is licensed under a Creative Commons Attribution NonCommercial 4.0 License (CC BY-NC 4.0).

CCopyright P.K. Bhattacharya and A. Roy, 2017

Licensee PAGEPress, Italy

Italian Journal of Medicine 2017; 11:15-22

doi:10.4081/itjm.2016.634 level resulting from defects in insulin secretion, insulin action, or both. Both forms are due to complex interplay between genetic susceptibility and environmental factors. Type-2 diabetes mellitus $\left(\mathrm{T}_{2} \mathrm{DM}\right)$, which accounts for $90 \%-95 \%$ cases, develops when insulin production is insufficient to overcome underlying insulin resistance. The prevalence of diabetes has increased rapidly during the past few decades, from 35 million in 1985 to nearly 387 million in 2014 and is projected to rise to 592 million in $2035 .^{1,2}$ This increase has occurred mainly in $\mathrm{T}_{2} \mathrm{DM}$ as compared to type- 1 diabetes mellitus $\left(\mathrm{T}_{1} \mathrm{DM}\right) . \mathrm{T}_{1} \mathrm{DM}$ has few known modifiable environmental risk factors. In case of $\mathrm{T}_{2} \mathrm{DM}$, since genetic background is unlikely to change during this short time period of few decades, the growing epidemic of $\mathrm{T}_{2} \mathrm{DM}$ is more likely due to changes in environmental factors. This increase in the prevalence of $\mathrm{T}_{2} \mathrm{DM}$ also closely parallels the global increase of obesity. ${ }^{3}$ The scope for primary prevention of $\mathrm{T}_{1} \mathrm{DM}$ is limited on the basis of current knowledge and is probably not appropriate. However, the development of prevention programs for $\mathrm{T}_{2} \mathrm{DM}$ based on elimination of environmental risk factors is possible.

The aim of this paper is to find evidence for primary prevention of $\mathrm{T}_{2} \mathrm{DM}$ based on epidemiological studies and clinical trials on the effects of lifestyle modification and drugs and the feasibility of applying these interventions in the prevention of $\mathrm{T}_{2} \mathrm{DM}$ in resource limited countries like India. 


\section{Data source and search strategy}

The literature search was aimed at identifying all epidemiological studies and randomized control trials pertaining to primary prevention of $\mathrm{T}_{2} \mathrm{DM}$. We searched online through the PubMed, Medline, EMBASE, Cochrane databases and Google Scholar search engine, using the keywords diabetes mellitus, type 2 diabetes mellitus, risk factors, primary prevention, and lifestyle modifications. We considered studies in English language only found by these search engines. Electronic searches were supplemented by hand searching of reference lists, reviews, relevant book chapters, conference abstracts, reports, organizational guidelines and specialist journals. We evaluated each paper for inclusion in this current study on the basis of the following criteria: i) study design: epidemiological studies and randomized controlled trial; ii) objective: Evidence of efficacy of preventive measures in primary prevention of $\mathrm{T}_{2} \mathrm{DM}$. The scheme of literature search is shown in Figure 1.

\section{Prevention of diabetes mellitus}

Prevention strategies for diabetes or for any chronic disease can be broadly categorized into four stages: i) primordial prevention; ii) primary prevention; iii) secondary prevention; and iv) tertiary prevention (Figure 2).

Primordial prevention is the adaptation of strategies during the phase of normal glucose tolerance to stop the emergence of the risk factors before they have appeared. The preventive measures comprise the maintenance of normal body weight through the adoption of healthy nutritional habits and physical exercise.

Primary prevention is possible during the stage of pre-diabetes [impaired fasting glucose (IFG)/impaired glucose tolerance (IGT)], before the development of diabetes mellitus.

Secondary prevention: preventive strategies that are carried out after diabetes have been detected to prevent or delay the development of long-term complications of the disease.

Tertiary prevention: it is carried out at the stage when complications have already set in, with the aim of preventing the progression of these complications.

\section{Rationale for preventive measures}

$\mathrm{T}_{2} \mathrm{DM}$ is associated with serious health problems. It is a major risk factor for cardiovascular diseases like coronary artery disease and stroke and is also a leading

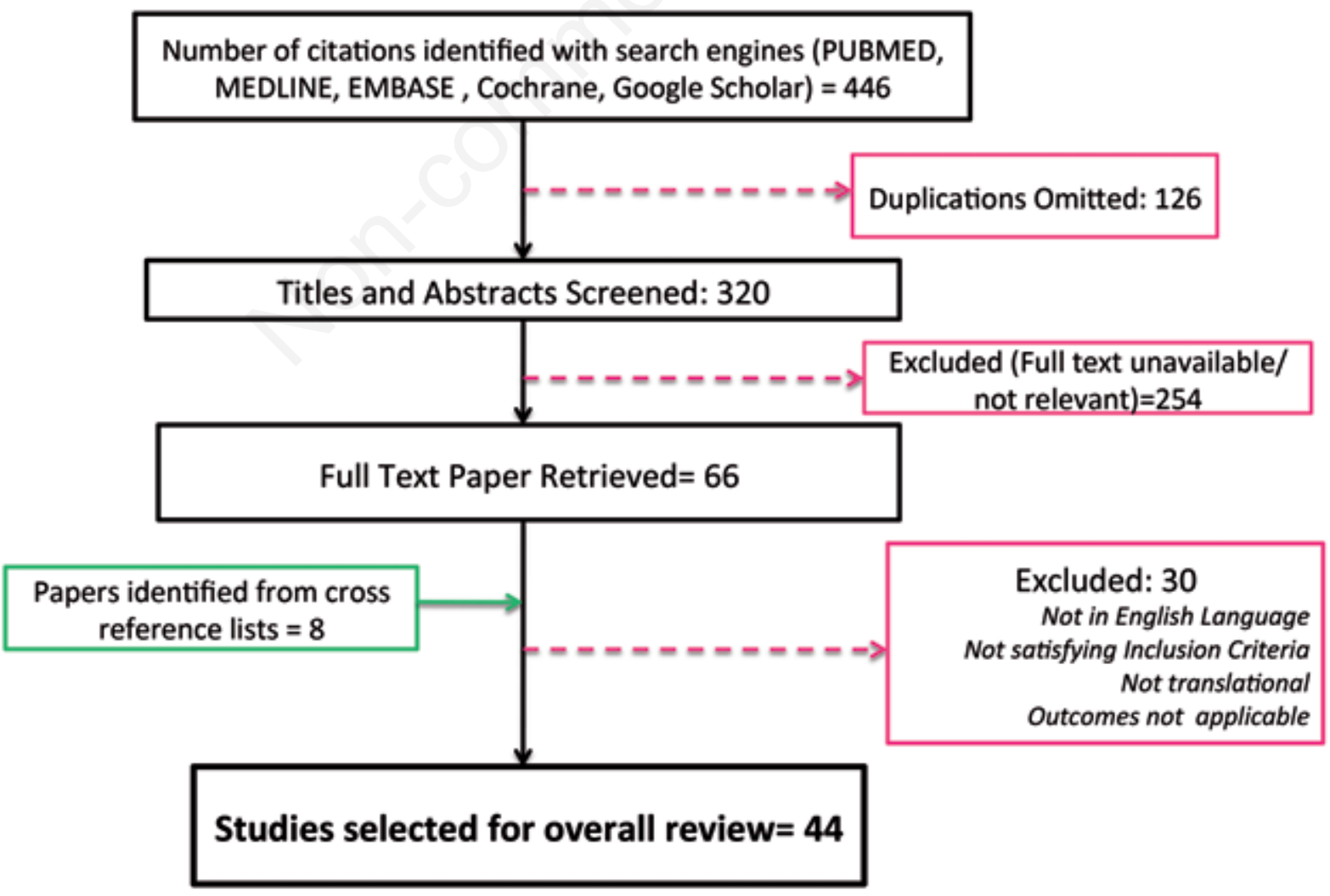

Figure 1. Flow chart showing scheme for literature search. 
cause of blindness, kidney failure, and non-traumatic amputations. The economic burden is enormous and will continue to rise with the rising prevalence of the disease. Since there is no cure for diabetes, primary prevention, by diet and lifestyle modifications (LSM) is of paramount importance. This would result in significant reduction in social burden and economic costs. ${ }^{4}$

\section{Feasibility of prevention}

$\mathrm{T}_{2} \mathrm{DM}$ has a long asymptomatic period in natural history. There are several risk factors for the development of the disease and people with one or more of these risk factors are more prone to develop the disease than the general population. There are safe and relatively simple screening tests, which can reliably identify the high-risk groups. Moreover, there are safe and potentially effective interventions, which are shown to reduce the development of the disease. ${ }^{5,6}$

\section{Major lifestyle risk factors for type-2 diabetes mellitus}

The major risk factors responsible for $\mathrm{T}_{2} \mathrm{DM}$ are obesity, physical activity, tobacco smoking, alcohol consumption and mental stress.

Obesity is the single most important risk factor for $\mathrm{T}_{2} \mathrm{DM}$. In a large prospective cohort study ${ }^{7}$ (Nurses' Health study) it was shown that the most important risk factors for $\mathrm{T}_{2} \mathrm{DM}$ were overweight and obesity.
The relative risks (RR) were 38.9 for a body mass index $(\mathrm{BMI}) \geq 35 \mathrm{~kg} / \mathrm{m}^{2}$ and 20.1 for a BMI of 30.0 to $34.9 \mathrm{~kg} / \mathrm{m}^{2}$, as compared with a BMI $<23 \mathrm{~kg} / \mathrm{m}^{2}$.

Physical activity: convincing epidemiologic data support the role of physical activity in preventing diabetes. Aerobic exercise by overweight and obese adults, results in modest weight loss, which is independent of the effect of caloric reduction through dieting. ${ }^{8}$ However, only part of the beneficial effect of physical activity on diabetes is mediated through body weight. Physical activity is clearly associated with increased insulin sensitivity. ${ }^{9}$ Further, it has been shown that sedentary behaviors such as prolonged television watching are strongly associated with obesity, weight gain, and risk of diabetes. However, this increased risk cannot entirely be explained by the decreased physical activity and unhealthy eating patterns associated with television watching. ${ }^{10}$

Smoking: several prospective studies showed that smoking modestly increases the risk of $\mathrm{T}_{2} \mathrm{DM} .{ }^{11,12} \mathrm{Al}$ though smoking cessation is associated with a modest increase in weight, it increases insulin sensitivity and improves the lipoprotein profile. ${ }^{13}$ Prospective studies clearly demonstrated that the beneficial effects of smoking cessation on diabetes risk outweigh the adverse effects on weight gain. ${ }^{14}$

Alcohol: effects of alcohol consumption on the risk of development of $\mathrm{T}_{2} \mathrm{DM}$ follow a U-shaped curve. While moderate consumption is shown to be associated with lower incidence, this beneficial effect is reversed with heavy consumption. ${ }^{15}$

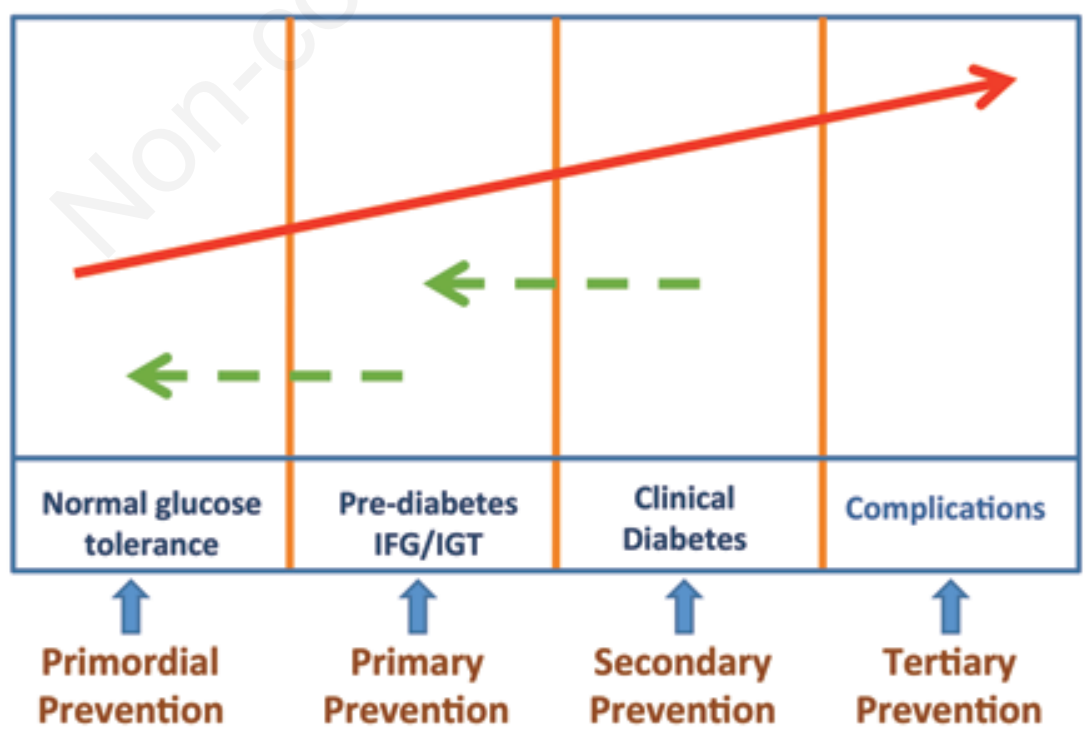

Figure 2. Showing the different stages in the development and progression of type-2 diabetes mellitus and the steps for various types of preventions. Red arrow shows steady progression from euglycemic stage through pre-diabetes into clinical diabetes and subsequent complications in the natural history of type-2 diabetes mellitus. Dotted green arrows show the possible effects of interventions in the prevention or reversion of progression of this process. IFG, impaired fasting glucose; IGT, impaired glucose tolerance. 
Stress: Recent observations ${ }^{16,17}$ have shown that increased mental stress and activation of the physiologic stress response from chronic exposure to stressors, low socioeconomic status (SES), severe mental health problems, or aggressive behavior increases the risk of $T_{2} D M$. Increased risk for $T_{2} D M$ has been found in people exposed to stressful working conditions or traumatic events, with depression; with personality traits or mental health problems that put them in conflict with others; or in people of low SES, either currently or in childhood and in racial/ethnic minority populations, independent of current SES. ${ }^{16}$

\section{Evidence for preventability of type-2 diabetes mellitus}

The evidence that $T_{2} D M$ is preventable comes from three major areas of research, namely from i) epidemiological, clinical trials on effect of ii) LSM and iii) drugs in development of $\mathrm{T}_{2} \mathrm{DM}$.

\section{Epidemiologic evidence for prevention of type-2 diabetes mellitus}

Strong epidemiologic evidence indicates that diabetes is associated with lifestyle patterns of populations. ${ }^{18}$ People who migrate to westernized countries, with their more sedentary lifestyles and westernized diets, were shown to have greater risk of developing
$\mathrm{T}_{2} \mathrm{DM}$ than do their counterparts, who remain in the native countries. ${ }^{19}$ Populations which have been undergoing westernization even in the absence of migration to the West, such as North American Indians ${ }^{20}$ and Western Samoans, ${ }^{21,22}$ also have experienced dramatic rises in obesity and $\mathrm{T}_{2} \mathrm{DM}$. Further, population studies, ${ }^{7,18,23}$ which have examined multiple risk factors simultaneously, e.g., the Nurses' Health Study ${ }^{7}$ have clearly defined a low-risk group for development of $\mathrm{T}_{2} \mathrm{DM}$ which are attributable to five variables: i) BMI $<25 \mathrm{~kg} / \mathrm{m}^{2}$; ii) diet high in cereal fiber and polyunsaturated fat and low in trans-fat and glycemic load; iii) engagement in moderate-to-vigorous physical activity for at least half an hour per day; iv) no current smoking; v) alcohol in moderation.

Women in low-risk group (3.4\%) had a RR of diabetes of 0.09 compared to rest of cohort and $91 \%$ of the diabetics were attributed to those five factors. These data provide strong epidemiologic evidence that the majority of $\mathrm{T}_{2} \mathrm{DM}$ cases could be prevented by the adoption of a healthier lifestyle.

\section{Clinical trials on lifestyle changes for prevention oftype-2 diabetes mellitus}

Clinical trials on lifestyle changes for prevention of $\mathrm{T}_{2} \mathrm{DM}$ are presented in Table 1:24-28

- Da Qing Study:24,25 577 subjects with IGT were randomly assigned to 4 groups (control, diet, exercise,

Table 1. Randomized trials on diet and lifestyle in prevention of type-2 diabetes mellitus in subjects with impaired glucose tolerance.

\begin{tabular}{|c|c|c|c|c|}
\hline Study population & $\begin{array}{l}\text { Da-Qing study }{ }^{24} \\
\text { (China) }\end{array}$ & $\begin{array}{c}\text { Finnish diabetes } \\
\text { prevention study }{ }^{27} \\
\text { (Finland) }\end{array}$ & $\begin{array}{c}\text { Diabetes prevention } \\
\text { program }^{26} \text { (USA) }\end{array}$ & $\begin{array}{c}\text { Indian diabetes } \\
\text { prevention program } \\
\text { (India) }\end{array}$ \\
\hline $\mathrm{N}$ (year) & 577 (1997) & $522(2002)$ & $3234(2001)$ & $531(2006)$ \\
\hline Age in years (mean age) & $>25(45.0)$ & $40-65(55)$ & $>25(50.6)$ & $35-55(45.9)$ \\
\hline Interventions arms & $\begin{array}{c}\text { Diet alone } \\
\text { Exercise alone } \\
\text { Diet + Exercise } \\
\text { Control }\end{array}$ & $\begin{array}{c}\text { LSM } \\
\text { Control }\end{array}$ & $\begin{array}{c}\text { LSM } \\
\text { Metformin } \\
\text { Control }\end{array}$ & $\begin{array}{c}\text { LSM } \\
\text { Metformin } \\
\text { LSM+Metformin } \\
\text { Control }\end{array}$ \\
\hline
\end{tabular}

\begin{tabular}{llllll}
\hline Follow-up (in years) & 6 & 3.2 & 2.8 & 3.5
\end{tabular}

\begin{tabular}{|c|c|c|c|c|}
\hline \multicolumn{5}{|l|}{ Outcomes } \\
\hline Weight change & $\begin{array}{l}\text { Weight loss in all groups } \\
\text { in subjects developing } \\
\text { diabetes; weight gain in } \\
\text { nondiabetics in control, } \\
\text { diet, and activity groups; } \\
\text { weight loss in } \\
\text { non-diabetics in diet } \\
\text { + exercise group }\end{array}$ & $\begin{array}{l}\text { Intervention group: } \\
-4.2 \mathrm{~kg}(-4.7 \%) \\
\text { Control group: } \\
-0.8 \mathrm{~kg}(-0.9 \%)\end{array}$ & $\begin{array}{c}\text { Lifestyle intervention } \\
\text { group: }-5.6 \mathrm{~kg} \\
\text { Metformin group: }-2.1 \mathrm{~kg} \\
\text { Control group: }-0.1 \mathrm{~kg}\end{array}$ & Not significant \\
\hline $\begin{array}{l}\text { Diabetes risk reduction } \\
\text { with intervention }\end{array}$ & $\begin{array}{c}\text { Diet only: } 31 \% \\
\text { Exercise only: } 46 \% \\
\text { Diet }+ \text { exercise: } 42 \%\end{array}$ & $58 \%$ & $\begin{array}{l}\text { Lifestyle intervention } \\
\text { group: } 58 \% \\
\text { Metformin group: } 31 \%\end{array}$ & $\begin{array}{c}\text { LSM- } 28.5 \% \\
\text { Metformin- } 26.4 \% \\
\text { LSM+ Metformin- } 28.2 \%\end{array}$ \\
\hline
\end{tabular}

LSM, lifestyle modifications. 
or diet plus exercise). Participants in the diet-intervention group were prescribed a diet with a specific fat content and with individual goals for cereal, vegetables, meat, milk, and oil intake. The intervention groups fared better than the controls in reducing risk of developing diabetes.

- Diabetes Prevention Program:26 3234 persons with IGT were randomly assigned to placebo, metformin (850 mg twice daily), or a LSM program targeting $\geq 7 \%$ weight loss and physical activity $\geq 150$ $\mathrm{min} /$ week. During the 2.8 years of follow-up, LSM reduced diabetes incidence by $58 \%$ compared to control group. LSM was equally effective in both men and women and in different ethnic groups.

- Finnish Diabetes Prevention Study: ${ }^{27} 522$ persons with IGT were randomly assigned to either a control group or an intervention group, where subjects received counselling aimed at reducing weight, total fat intake, and saturated fat intake and increasing both intake of fiber and physical activity. The intervention resulted in an overall risk reduction of 58\%.

- Indian Diabetes Prevention Program: $:^{28} 531$ native Asian Indians with IGT were randomized to either: i) LSM; ii) metformin; iii) LSM plus metformin; and iv) controls. While the progression of IGT to diabetes was high, both LSM and metformin significantly reduced the incidence of diabetes in these Asian Indians with IGT but there was no added benefit from combining both.

\section{Drug trials for prevention of type-2 diabetes mellitus}

- Diabetes Prevention Program: ${ }^{26}$ The metformin group experienced a $31 \%$ diabetes risk reduction over a 3-year intervention period compared with the controls, although this effect was considerably smaller than that observed for the LSM group (58\%).

- Study to Prevent Non-Insulin-Dependent Diabetes Mellitus (STOPNIDDM): ${ }^{29}$ In this multicenter trial in Austria, Canada, Germany, Denmark, Finland, Israel, Norway, Spain, and Sweden, 1429 subjects with IGT were randomly assigned to either an acarbose intervention or a placebo group. The intervention group had a $25 \%$ diabetes risk reduction compared to placebo.

- Troglitazone in Prevention of Diabetes study (TRI$P O D):{ }^{30} 266$ women with a history of gestational diabetes and at high risk of developing $\mathrm{T}_{2} \mathrm{DM}$ were randomly assigned to troglitazone treatment (400 $\mathrm{mg} / \mathrm{d}$ ) or placebo. During 3.5 years, treatment group resulted in a $55 \%$ lower diabetes risk compared with placebo. However, troglitazone was eventually retired on account of its associated hepato-toxicity.

- Post-hoc analyses of drug intervention trials in cardiovascular disease: post-hoc analyses of several drug intervention trials with cardiovascular diseases as primary outcomes suggest that antihypertensive and cholesterol-lowering medications can prevent $\mathrm{T}_{2} \mathrm{DM}$ : i) Heart Outcomes Prevention Evaluation (HOPE) trial: Among 5720 patients without known diabetes but with vascular disease at baseline, patients randomized to receive treatment with ramipril had a RR of 0.66 [95\% confidence interval (CI): 0.51-0.85] to develop $\mathrm{T}_{2} \mathrm{DM}$ over a 4.5 -year period compared with those who received placebo; ${ }^{31}$ ii) West of Scotland Coronary Prevention Study (WESCOPS): The WESCOPS study concluded that the assignment to Pravastatin therapy resulted in a $30 \%$ reduction $(\mathrm{P}=0.042)$ in the hazard of becoming diabetic. ${ }^{32}$ However, on the contrary, other studies ${ }^{33}$ have concluded that pravastatin did not reduce the incidence of diabetes. Furthermore a recent metaanalysis has suggested that statin therapy was associated with a $9 \%$ increased risk for incident diabetes (odds ratio 1.09; 95\% CI: 1.02-1.17); ${ }^{34}$ iii) Losartan Intervention For Endpoint reduction in hypertension study (LIFE): fewer hypertensive patients with left ventricular hypertrophy developed $\mathrm{T}_{2} \mathrm{DM}$ if they were treated with losartan (angiotensin II antagonist) than if they were treated with atenolol $(\beta$ blocker), (RR: $0.75,95 \%$ CI: 0.63 to 0.88$).{ }^{35}$ In the post hoc analysis of the HOPE trial, ramipril was associated with a $34 \%$ reduction in the risk of newonset diabetes (RR: 0.66 ; 95\% CI: $0.51-0.85$; $\mathrm{P}<0.001)$ when compared with placebo. ${ }^{31}$

Analysis of the major trials has uniformly shown that drug treatments were less effective than LSM and could cause side effects. In contrast, healthy diet and LSM were effective not only in preventing diabetes but also in reducing risk of other chronic diseases such as coronary artery disease ${ }^{36}$ and colon cancer. ${ }^{37}$ Majority of the LSM intervention studies followed subjects with IGT/IGF between 3-20 years. ${ }^{38}$ While the western studie ${ }^{26,27}$ targeted weight reduction in obese subjects by LSM, the Asian studies ${ }^{24,28}$ had relatively leaner subjects and weight loss was not a major contributor to improved outcome of LSM.

\section{Dietary patterns and risk for diabetes}

High consumption of vegetables, fruits, fish, poultry, and whole grains was associated with a modest risk reduction for $\mathrm{T}_{2} \mathrm{DM}$, whereas a Western pattern, characterized by high consumption of red meat, processed meat, French fries, high-fat dairy products, refined grains, sweets and desserts, was associated with an increased risk. ${ }^{39,40}$ In the Nurses' Health Study, ${ }^{7} \mathrm{Hu}$ et al. found that an a priori-defined pattern score based on the intake of cereal fiber, polyunsaturated fatty acids, trans-fatty acids, and glycemic load had a tremendous effect on diabetes incidence. Women within the highest quintile of the pattern score 
had a RR of 0.49 (95\% CI: 0.42-0.56) compared with women in the lowest quintile.

\section{Translation of diabetes prevention into community practice}

Wide gap exists between scientific knowledge derived from research and its practical application. A broad-based public health perspective is needed to control the diabetes epidemic. The Centers for Disease Control and Prevention (CDC)-led National Diabetes Prevention Program (NDPP) is an evidence-based lifestyle change program for preventing $\mathrm{T}_{2} \mathrm{DM},{ }^{41}$ based on the results of the DPP. ${ }^{26}$ This year-long program helps participants make real lifestyle changes such as eating healthier, incorporating physical activity into their daily lives, and improving problem-solving and coping skills.

\section{Feasibility of prevention programs}

Follow up of the patients of the DPP program ${ }^{26}$ showed that the incidence of $\mathrm{T}_{2} \mathrm{DM}$ was reduced by $58 \%$ with LSM and $31 \%$ with metformin in 2.8-year follow up. On 10-year follow-up ${ }^{42}$ the original LSM group maintained a reduced risk for diabetes by $34 \% .{ }^{42}$ Individuals $>60$ years were more successful, showing a decreased risk of progression to diabetes by $49 \% .{ }^{42}$ Although results were groundbreaking, cost of intensive individual counseling model in LSM group was high (\$1400/participant). ${ }^{43}$ However, these results could be replicated at a much lower cost in a community-based group setting in the YMCA-DEPLOY study (Y-DPP), thereby reducing costs to \$275-325 per participant. ${ }^{44}$ Although it was subsequently taken up by CDC as the NDPP, it could cover only a fraction of the 85-90 million pre-diabetics of USA.

In contrast to western population, in Asian Indians progression rate of IGT to diabetes was very high: $18.3 \%$ per year with a cumulative incidence of $55.0 \%$ in 3 years, as compared to Europeans (Finnish - 6\%; US - 11/person-years) and Chinese (11.3\%). ${ }^{28}$ Weight reduction was not a major determinant of benefit and the subjects were mostly lean with high insuline resistance (IR). ${ }^{45}$ Nevertheless, subjects with high IR and low BMI also benefited from LSM. ${ }^{46,47}$

In India, the estimated treatment cost of diabetes is \$ $140-150 /$ person/year. ${ }^{38}$ Prevention or delay in diabetes by LSM would result in a net gain in healthcare investments. ${ }^{48}$ It is necessary to develop pragmatic, cost effective strategies for primary prevention to extend the benefits in community. Recent studies using information technology such as mobile phone-based SMS were tested for this purpose.$^{49}$ In a recent 2-year program in India, effectiveness of SMS in educating and motivating men with IGT to follow LSM was demonstrated and was found to be highly effective with a relative risk reduction of $36 \%$ compared to the participants who had only standard care. ${ }^{49}$ Future plan should focus on health education of the public, improving the national capacity to detect and manage non-communicable diseases and development of innovative, cost effective, and scalable methodologies. ${ }^{38}$ Examples of national programs like the Finnish $\mathrm{DEKHO}^{50}$ and in Singapore ${ }^{51}$ should be taken as model endeavors to formulate strategies to promote and implement community health programs.

\section{Conclusions}

Prevalence of diabetes has increased manifold worldwide during past few decades; the increase occurring mainly in $\mathrm{T}_{2} \mathrm{DM}$ compared to $\mathrm{T}_{1} \mathrm{DM}$, is more likely due to changes in environmental risk factors. Epidemiologic studies, LSM and medications have conclusively proved that primary prevention, targeted during the stage of pre-diabetes prevents and/or delays the onset of diabetes. The positive effects are more profound and safer with LSM as compared to medications. This is shown to be effective globally, across various ethnicities and races, and sustainable on longterm follow-up. However, these interventions are expensive, even according to the western standards. Similar results have been shown to be replicated at much lower cost in community-based settings in USA but it could cover only a fraction of pre-diabetics of the country. Similar low-cost community based programs of primary prevention are essential for developing countries like India where the burden of diabetes is much higher.

\section{References}

1. World Health Organization (WHO). The world health report 2002 - Reducing Risks, Promoting Healthy Life. Available from: http://www.who.int/whr/2002/en/ Accessed: 30 May, 2015.

2. International Diabetes Federation (IDF). Atlas 2014. Available from: https://www.idf.org/sites/default/files/ Atlas-poster-2014_EN.pdf Accessed: 30 May, 2015.

3. World Health Organization (WHO). Diet, nutrition and the prevention of chronic diseases. Report of the joint WHO/FAO expert consultation. WHO Technical Report Series, No. 916 (TRS 916). Available from: http:// whqlibdoc.who.int/trs/who_trs_916.pdf Accessed: 30 May, 2015.

4. Herman WH. The economics of diabetes prevention. Med Clin North Am 2011;95:373-84.

5. Bantle JP, Wylie-Rosett J, Albright AL, et al. Nutrition recommendations and interventions for diabetes: a position statement of the American Diabetes Association. Diabetes Care 2008;31:S61-78. 
6. Nyenwe EA, Jerkins TW, Umpierrez GE, Kitabchi AE. Management of type 2 diabetes: evolving strategies for the treatment of patients with type 2 diabetes. Metabolism 2011;60:1-23.

7. Hu FB, Manson JE, Stampfer MJ, et al. Diet, lifestyle, and the risk of type 2 diabetes mellitus in women. $\mathrm{N}$ Engl J Med 2001;345:790-7.

8. National Institute of Health (NIH). Clinical guidelines on the identification, evaluation, and treatment of overweight and obesity in adults: the evidence report. NIH Publication No. 98-4083. U.S. Department of Health and Human Services; September 1998 Available from: http://www.nhlbi.nih.gov/files/docs/guidelines/ob_gdln. pdf Accessed: 30 May, 2015.

9. Duncan GE, Perri MG, Theriaque DW, et al. Exercise training, without weight loss, increases insulin sensitivity and postheparin plasma lipase activity in previously sedentary adults. Diabetes Care 2003;26:557-62.

10. Hu FB, Li TY, Colditz GA, et al. Television watching and other sedentary behaviors in relation to risk of obesity and type 2 diabetes mellitus in women. JAMA 2003;289:1785-91.

11. Jee SH, Foong AW, Hur NW, Samet JM. Smoking and risk for diabetes incidence and mortality in Korean men and women. Diabetes Care 2010;33:2567-72.

12. Willi C, Bodenmann P, Ghali WA, et al. Active smoking and the risk of type 2 diabetes: a systematic review and meta-analysis. JAMA 2007;298:2654-64.

13. Eliasson B, Attvall S, Taskinen MR, Smith U. Smoking cessation improves insulin sensitivity in healthy middleaged men. Eur J Clin Invest 1997;27:450-6.

14. Will JC, Galuska DA, Ford ES, et al. Cigarette smoking and diabetes mellitus: evidence of a positive association from a large prospective cohort study. Int J Epidemiol 2001;30:540-6.

15. Schulze MB, Hu FB. Primary prevention of diabetes: what can be done and how much can be prevented? Annu Rev Public Health 2005;26:445-67.

16. Kelly SJ, Ismail M. Stress and type 2 diabetes: stress and type 2 diabetes: a review of how stress contributes to the development of type 2 diabetes. Annu Rev Public Health 2015;36:441-62.

17. Pouwer F, Kupper N, Adriaanse MC. Does emotional stress cause type 2 diabetes mellitus? A review from the European Depression in Diabetes (EDID) Research Consortium. Discov Med 2010;9:112-8.

18. Hu FB. Globalization of diabetes The role of diet, lifestyle, and genes. Diabetes Care 2011;34:1249-57.

19. Manson JE, Spelsberg A. Primary prevention of non-insulin-dependent diabetes mellitus. Am J Prev Med 1994;10:172-84.

20. Gohdes D, Kaufman S, Valway S. Diabetes in American Indians. An overview. Diabetes Care 1993;16:239-43.

21. Collins VR, Dowse GK, Toelupe PM, et al. Increasing prevalence of NIDDM in the Pacific island population of Western Samoa over a 13-year period. Diabetes Care 1994; 17:288-96.

22. Hodge AM, Dowse GK, Toelupe P, et al. Dramatic increase in the prevalence of obesity in Western Samoa over the 13 year period 1978-1991. Int J Obes Relat Metab Disord 1994;18:419-28.

23. Koppes LL, Dekker JM, Hendriks HF, et al. Moderate alcohol consumption lowers the risk of type 2 diabetes: a meta-analysis of prospective observational studies. Diabetes Care 2005;28:719-25.

24. Pan XR, Li GW, Hu YH, et al. Effects of diet and exercise in preventing NIDDM in people with impaired glucose tolerance. The Da Qing IGT and Diabetes Study. Diabetes Care 1997;20:537-44.

25. Pendergrass M, Li G, Zhang P, et al. The long-term effect of lifestyle interventions to prevent diabetes in the China Da Qing Diabetes Prevention Study: a 20-year follow-up study. Diabetes Care 2008;31:1921-2.

26. Knowler WC, Barrett-Connor E, Fowler SE, et al. Reduction in the incidence of type 2 diabetes with lifestyle intervention or metformin. N Engl J Med 2002;346: 393-403.

27. Tuomilehto J, Lindstrom J, Eriksson JG, et al. Prevention of type 2 diabetes mellitus by changes in lifestyle among subjects with impaired glucose tolerance. N Engl J Med 2001;344:1343-50.

28. Ramachandran A, Snehalatha C, Mary S, et al. The Indian Diabetes Prevention Programme shows that lifestyle modification and metformin prevent type 2 diabetes in Asian Indian subjects with impaired glucose tolerance (IDPP-1) IDPP-1. Diabetologia. 2006;49:289-97.

29. Chiasson JL, Josse RG, Gomis R, et al. Acarbose for prevention of type 2 diabetes mellitus: theSTOP-NIDDMrandomised trial. Lancet 2002;359:2072-7.

30. BuchananTA, Xiang AH, Peters RK, et al. Preservation of pancreatic beta-cell function and prevention of type 2 diabetes by pharmacological treatment of insulin resistance in high-risk hispanic women. Diabetes 2002; 51:2796-803.

31. Yusuf S, Gerstein H, Hoogwerf B, et al. 2001. Ramipril and the development of diabetes. JAMA 2002;286: 1882-85.

32. Freeman DJ, Norrie J, Sattar N, et al. Pravastatin and the development of diabetes mellitus: evidence for a protective treatment effect in theWest of Scotland Coronary Prevention Study. Circulation 2001;103:357-62.

33. Keech A, Colquhoun D, Best J, et al. Secondary prevention of cardiovascular events with long-term pravastatin in patients with diabetes or impaired fasting glucose results from the LIPID trial. Diabetes Care 2003;26:2713-21.

34. Sattar N, Preiss D, Murray HM, et al. Statins and risk of incident diabetes: a collaborative meta-analysis of randomised statin trials. The Lancet 2010;375:735-42.

35. Lindholm LH, Ibsen H, Borch-Johnsen K, et al. Risk of new-onset diabetes in the Losartan Intervention for Endpoint reduction in hypertension study. J Hypertens 2002;20:1879-86.

36. Stampfer MJ, Hu FB, Manson JE, et al. Primary prevention of coronary heart disease in women through diet and lifestyle. N Engl J Med 2000;343:16-22.

37. Slattery ML. Diet, lifestyle, and colon cancer. Semin Gastrointest Dis 2000;11:142-6.

38. Ramachandran A, Snehalatha C. Prevention of diabetes: How far have we gone? Ind J End Met 2014;18:252-3.

39. Fung TT, Schulze MB, Manson JE, et al. Dietary patterns, meat intake and the risk of type 2 diabetes in women. Arch Intern Med 2004;164:2235-40.

40. van Dam RM, Rimm EB, Willett WC, et al. Dietary patterns and risk for type 2 diabetes mellitus in U.S. men. Ann Intern Med 2002;136:201-9.

41. Centers for Disease Control and Prevention (CDC). Na- 
tional Diabetes prevention program 2015. Available from: https://www.cdc.gov/diabetes/prevention/index. html Accessed: 10 June, 2015.

42. Knowler WC, Fowler SE, Hamman FR, et al. 10-year follow-up of diabetes incidence and weight loss in the Diabetes Prevention Program Outcomes Study. Lancet 2009;374:1677-86.

43. Anderson J, Riley M, Everette TD. How proven primary prevention can stop diabetes. Clin Diabetes 2012;30:76-9.

44. Ackermann RT, Finch EA, Brizendine E, Zhou HDG. Translating the Diabetes Prevention Program into the community. Deploy Piloy Study. Am J Prev Med 2008; 35:357-63.

45. Ramachandran A, Snehalata C. Diabetes prevention programs. Med Clin North Am 2011;95:353-72.

46. Baker MK, Simpson K, Lloyd B, et al. Behavioral strategies in diabetes prevention programs: a systematic review of randomized controlled trials. Diabetes Res Clin Pract 2011;91:1-12.

47. Snehalatha C, Mary S, Selvam S, et al. Changes in Insulin secretion and insulin sensitivity in relation to the glycaemic outcomes in subjects with impaired glucose tolerance in the Indian Diabetes Prevention Programme1 (IDPP-1). Diabetes Care 2009;32:1796-801.

48. Jamison DT, Breman JG, Measham AR, et al. Disease control priorities in developing countries. 2nd Ed. New York: Oxford University Press; 2006. pp 591-603.

49. Ramachandran A, Snehalatha C, Ram J, et al. Effectiveness of mobile phone messaging in prevention of type 2 diabetes by lifestyle modification in men in India: a prospective, parallel-group, randomized controlled trial. Lancet Diabetes Endocrinol 2013;1:191-8.

50. Finnish Diabetes Association. Development programme for the prevention and care of diabetes (Dehko 20002010); edited by Leena Etu-Seppälä. Available from: http://www.diabetes.fi/en/finnish_diabetes_association/dehko Accessed: 10 June, 2015.

51. Ministry of Health. WHO Global Infobase: National Health Survey 2004, Singapore. Available from: http://www.singstat.gov.sg/docs/default-source/defaultdocument-library/publications/publications_and_papers/health/ssnsep05-pg19-20.pdf Accessed: 10 June 